\title{
Current Status and Future Prospects of Ammonothermal Bulk GaN Growth
}

\author{
Tadao Hashimoto*, Edward Letts and Sierra Hoff \\ SixPoint Materials, Inc., 37 Industrial Way, 106, Buellton, CA 93427, USA
}

(Received September 26, 2012; accepted December 17, 2012)

Key words: ammonothermal growth, bulk GaN, dislocation density, optical absorption

This paper reviews the current status of ammonothermal GaN growth at SixPoint Materials, Inc., and discusses challenges in the commercialization of the technology. Small prototype bulk GaN crystals show a high-quality microstructure as well as improved transparency. The full width at half maximum of the X-ray rocking curves from 002 and 201 diffractions typically ranges from a few tens to a few hundred arcsec. The minimum optical absorption coefficient at $450 \mathrm{~nm}$ is currently $4 \mathrm{~cm}^{-1}$. To commercialize this technology, expansion of the crystal size is essential. Future tasks include the development of a large reactor, the preparation of large seed crystals and the reduction of the number of cracks in crystals.

\section{Introduction}

GaN-based optoelectronic and electronic devices have made extraordinary progress over the last two decades. The most astonishing point of this progress is that the vast majority of devices have been developed on heteroepitaxial substrates with a large lattice mismatch such as sapphire and silicon carbide. In the history of compound semiconductor technology, no other material system with a large lattice mismatch has achieved a greater level of maturity in device performance than group III nitrides, yet higher performance at a lower cost is continuously demanded. A new breakthrough is needed to overcome the current issues, and bulk GaN crystals, which enable the homoepitaxial growth of GaN-based devices on any preferable orientation, have been regarded as the most effective and practical solution to many problems associated with heteroepitaxy. However, owing to the high melting point and the high equilibrium nitrogen pressure at high temperatures, it is extremely challenging to grow bulk GaN crystals of appreciable size. Currently, hydride vapor phase epitaxy (HVPE) provides

${ }^{*}$ Corresponding author: e-mail: tadao@spmaterials.com 
the best solution to obtaining free-standing GaN wafers by a so-called "quasi-bulk" approach, i.e., the growth of a very thick film of $\mathrm{GaN}$ on a heteroepitaxial substrate by HVPE followed by the removal of the substrate. ${ }^{(1)}$ In addition, several attempts ${ }^{(2,3)}$ have been made to grow bulk GaN crystals on "quasi-bulk" GaN wafers by HVPE. Nevertheless, the reduction of dislocation density in GaN crystals grown on "quasibulk" GaN wafers by HVPE is somewhat limited; current state-of-the-art HVPE-grown GaN substrates have a dislocation density on the order of high $10^{5}$ to low $10^{6} \mathrm{~cm}^{-2}$. In addition, HVPE is inherently a cost-ineffective method because it utilizes an openreactor system, which requires a constant flow of reactive gases and Ga precursor.

Several approaches have been attempted to grow bulk GaN crystals from solutions in closed reactors, e.g., high-pressure solution growth, ${ }^{(4,5)}$ low-pressure solution growth with flux ${ }^{(6,7)}$ and ammonothermal growth. ${ }^{(8-10)}$ Despite the advantage of scalability over its counterparts, a limited number of research institutes have researched ammonothermal growth because the growth rate is relatively low and high-pressure ammonothermal reactors are not commercially available. Since Dwiliński et al. demonstrated bulk GaN with outstanding crystal quality, ${ }^{(11)}$ ammonothermal growth has drawn more attention from the nitride research community. On the basis of ammonothermal technologies at the University of California, Santa Barbara (UCSB), ${ }^{(12)}$ we started a venture company called SixPoint Materials, Inc., to develop ammonothermal GaN growth for commercial applications. In this article, we will review and update the status of ammonothermal GaN growth at SixPoint. After a brief introduction giving general information on the ammonothermal method, we will introduce the fundamental characteristics of bulk GaN crystals grown by SixPoint's proprietary ammonothermal method as well as future prospects towards their commercialization.

\section{Ammonothermal Growth}

\subsection{Fundamentals of ammonothermal growth}

A crystal growth method utilizing a supercritical solvent is generally called solvothermal growth. Solvothermal growth typically utilizes an autoclave, which can contain the supercritical solvent at a high pressure and high temperature. The most successfully commercialized example of solvothermal growth is the hydrothermal growth of $\alpha$-quartz, in which silica is dissolved in supercritical water and recrystallized on seed crystals. Solvothermal growth has the advantage of scalability over other crystal growth methods. Nowadays, hydrothermal quartz autoclaves can grow over 1000 crystals in one batch. Ammonothermal growth is a type of solvothermal growth using ammonia as a solvent, which is mainly used to grow nitride materials. In general, the growth mechanism of $\mathrm{GaN}$ by ammonothermal growth is explained as follows: 1) a nutrient, such as metallic $\mathrm{Ga}$ or polycrystalline $\mathrm{GaN}$, is placed in a nutrient region and dissolved in supercritical ammonia under a high pressure (100-400 $\mathrm{MPa}$ ) and high temperature $\left.\left(400-600^{\circ} \mathrm{C}\right) ; 2\right)$ the dissolved solute is transported by the convective flow of the solvent (i.e., supercritical ammonia) to a seed region; 3) the solvent becomes supersaturated in the seed region under a different temperature and/or pressure from those in the nutrient region; and 4) GaN crystallizes on seed crystals. Schematic drawings of typical 
ammonothermal growth setups are shown in Fig. 1. An autoclave heated by external heaters houses internal components and source materials. The heater is divided into two or more regions; the lower region is usually maintained at a higher temperature than the upper region. The configuration differs depending on the acidity of the supercritical ammonia because the temperature dependence of the solubility varies with the acidity of the supercritical ammonia. ${ }^{(13)}$ In the case of basic ammonothermal growth, the nutrient is located in the upper region of the autoclave and seed crystals are located in the lower region as shown in Fig. 1(a). In contrast, seed crystals are located in the upper region and the nutrient is located in the lower region for acidic ammonothermal growth as shown in Fig. 1(b).

\subsection{Development history and current status of ammonothermal GaN growth}

The first ammonothermal growth of group III nitride crystals was the synthesis of AlN reported in 1990.(14) Surprisingly, the result in this report already implied the retrograde solubility of group III nitride materials in ammonobasic solutions. In 1995, the synthesis of $\mathrm{GaN}$ in an ammonobasic environment was reported, ${ }^{(15)}$ which was followed by reports of growth in an ammonoacidic environment ${ }^{(16)}$ and an ammonobasic environment. ${ }^{(9)}$ After these pioneering works on microcrystalline $\mathrm{GaN}$ synthesis, research started to focus on the seeded growth of GaN via fluid transport. ${ }^{(17)}$ The retrograde solubility of $\mathrm{GaN}$ in an ammonobasic solution was reported in a technical journal in $2005^{(18)}$ as well as in a patent application, ${ }^{(19)}$ while research on ammonoacidic conditions revealed a normal dependence of solubility on temperature. ${ }^{(20)}$ In 2007 , the main focus of ammonothermal $\mathrm{GaN}$ growth shifted from thick-film growth to bulk growth, ${ }^{(21)}$ and an exceptionally

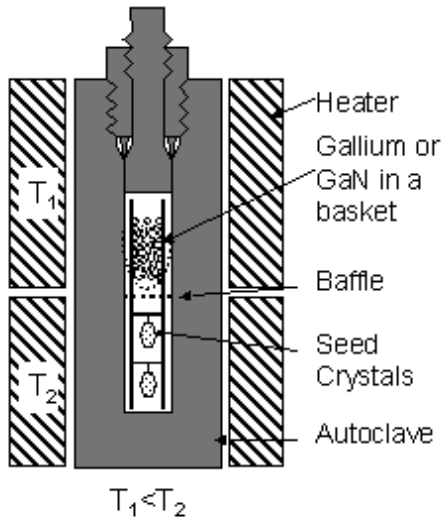

(a)

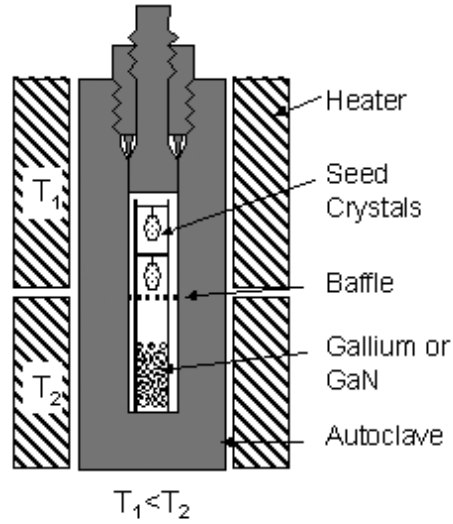

(b)

Fig. 1. Schematic drawings of ammonothermal growth setups. (a) Configuration for basic ammonothermal growth and (b) configuration for acidic ammonothermal growth. Note the difference in the nutrient and seed positioning. 
high quality GaN bulk crystal was demonstrated in 2008. ${ }^{(1)}$ Since these reports on bulk-shaped $\mathrm{GaN}$, ammonothermal growth has drawn more attention from the research community involved in GaN crystal growth.

Currently, there are several companies and institutes researching and developing the ammonothermal growth of GaN such as SixPoint Materials, Inc., Soraa, Inc., UCSB, and the Air Force Research Laboratory (AFRL) in the U.S.A.; Ammono S.A. in Poland; Mitsubishi Chemical Corp., Asahi Chemical Corp. and Tohoku University in Japan. There are three main approaches to growing GaN in supercritical ammonia: 1) the basic ammonothermal method with external heaters, 2) the acidic ammonothermal method with external heaters, and 3) the acidic high-temperature ammonothermal method with internal heaters. Table 1 summarizes the typical growth configurations.

\subsection{Experimental procedure}

The crystals discussed in this article were grown using ammonothermal autoclaves made of a Ni-Cr-based superalloy with 1" inner diameter. The inner space of the autoclave was divided into two regions: a nutrient region and a seed region with a baffle. The growth temperature was in the range from 500 to $600^{\circ} \mathrm{C}$ and the resulting ammonia pressure was in the range from 100 to $300 \mathrm{MPa}$. Polycrystalline GaN and/or metallic Ga was used as the nutrient, and free-standing $\mathrm{GaN}$ platelets were used as seed crystals. Both the polycrystalline $\mathrm{GaN}$ and free-standing $\mathrm{GaN}$ platelets were prepared by a vapor phase growth method. The growth rate varied from 10 to $400 \mu \mathrm{m} / \mathrm{d}$ depending on the growth conditions. Bulk GaN crystals having thicknesses of $5 \mathrm{~mm}$ were routinely obtained. The bulk GaN crystals were sliced with a multiple wire saw and the sliced wafers were lapped with diamond slurry and polished with colloidal silica.

The thicknesses of seeds, grown crystals and sliced wafers were measured with a micrometer. The structural quality was evaluated from the full width at half maximum (FWHM) of the X-ray rocking curves (XRCs) obtained from both 002 and 201 diffractions. The XRCs were collected using a high-resolution four-axis X-ray diffractometer (Philips) with a $\mathrm{Cu}$ anode operated at $40 \mathrm{~mA}$ and $45 \mathrm{keV}$ and a fourcrystal Ge (002) monochromator. Impurities in the grown crystals were quantified by secondary ion mass spectroscopy (SIMS) carried out at Evans Analytical Group, LLC. The optical absorption of the crystals was measured with a spectrophotometer (Shimadzu).

Table 1

Summary of current major activity of ammonothermal growth.

\begin{tabular}{llll}
\hline & Basic & Acidic & Acidic high-temperature \\
\hline Growth configuration & $\begin{array}{l}\text { Seeds: lower region } \\
\text { Nutrient: upper region }\end{array}$ & $\begin{array}{l}\text { Seeds: upper region } \\
\text { Nutrient: lower region }\end{array}$ & $\begin{array}{l}\text { Seeds: upper region } \\
\text { Nutrient: lower region }\end{array}$ \\
\hline Temperature range $\left({ }^{\circ} \mathrm{C}\right)$ & $400-600$ & $400-600$ & $600-1500$ \\
\hline Pressure range $(\mathrm{MPa})$ & $100-400$ & $100-400$ & $100-400$ \\
\hline Mineralizers & $\begin{array}{l}\text { Alkali metals and their } \\
\text { compounds }\end{array}$ & Halide compounds & Halide compounds \\
\hline
\end{tabular}




\section{Properties of Bulk GaN Crystals and Wafers}

\subsection{Current Status of Bulk GaN Growth}

At SixPoint, bulk GaN crystals with a size of 5-15 mm and thickness of 3-10 mm are routinely grown. Figure 2 shows examples of bulk GaN crystals. The FWHM of the XRCs from both 002 and 201 diffractions ranges from a few tens of arcsec to a few hundred arcsec depending on the growth conditions. The FWHM of the XRC from the 002 diffraction of the bulk GaN crystal shown at the top of Fig. 2 was approximately 30 arcsec as presented in Fig. 3. Analysis of X-ray diffraction confirmed that the FWHMs from both the on-axis (e.g., 002 diffraction) and off-axis (e.g., 201 diffraction) are similar. This phenomenon is not common for the heteroepitaxial growth of GaN thin

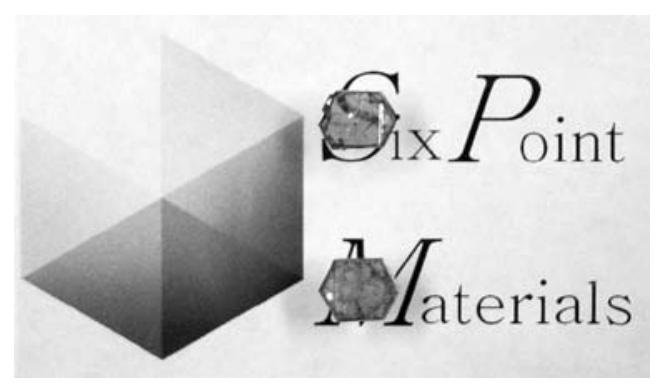

Fig. 2. Examples of GaN bulk crystals grown by the ammonothermal method.

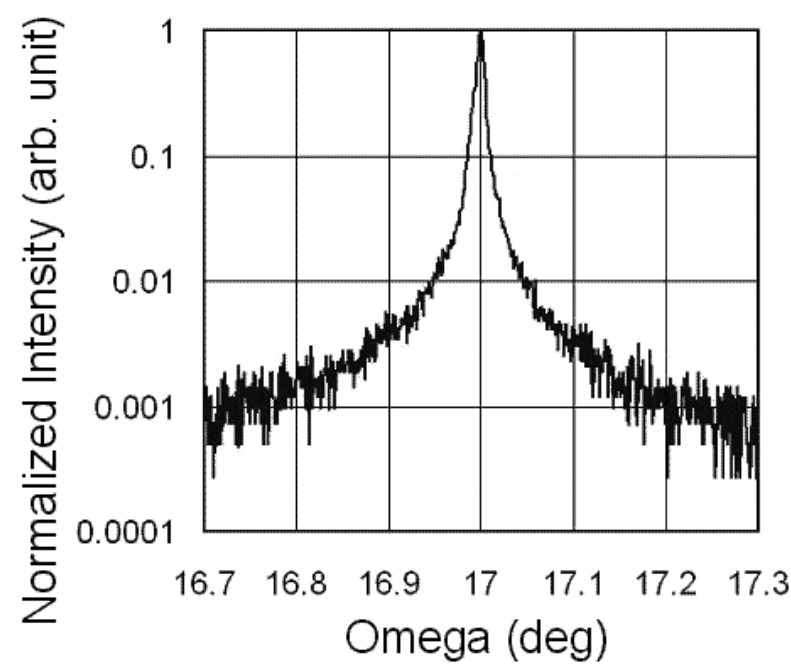

Fig. 3. Omega scan of $002 \mathrm{X}$-ray diffraction from the bulk GaN crystal at the top of Fig. 2. 
films in which edge-type and mixed-type dislocations are dominant. We consider that increasing the thickness of the bulk crystals improves the microstructure, especially in terms of reducing the edge component of dislocations.

The optical absorption at $450 \mathrm{~nm}$, which is a typical emission wavelength of blue LEDs used to excite the yellow phosphor in white LEDs, ranges from 4 to $20 \mathrm{~cm}^{-1}$, depending on the growth conditions. For LED applications, the optical absorption of a substrate must be minimized to increase the external quantum efficiency. To analyze the origin of the crystal color, GaN crystals intentionally doped with oxygen were grown by the ammonothermal method. Figure 4 shows the relationship between the optical absorption coefficient at $450 \mathrm{~nm}$ and the oxygen concentration measured by SIMS. The optical absorption has an obvious correlation with the oxygen concentration in the crystal. On the basis of this result, we attempted to minimize the amount of oxygen in the crystal through optimization of the growth conditions. As shown in Fig. 4, we succeeded in reducing the absorption coefficient to $4 \mathrm{~cm}^{-1}$ at $450 \mathrm{~nm}$. Since HVPEgrown GaN substrates have an absorption coefficient of 1 to $2 \mathrm{~cm}^{-1}$, we are confident that further optimization of the growth conditions will achieve an ammonothermal GaN substrate with transparency comparable to that of HVPE-grown GaN substrates.

Bulk GaN crystals grown by the ammonothermal method are readily sliced into wafers. Figure 5 shows an example of small GaN wafers sliced from a single crystal. More than ten wafers can be obtained from a single bulk crystal. The sliced wafers can be lapped and polished to achieve an epi-ready surface. Figure 6 shows an example of

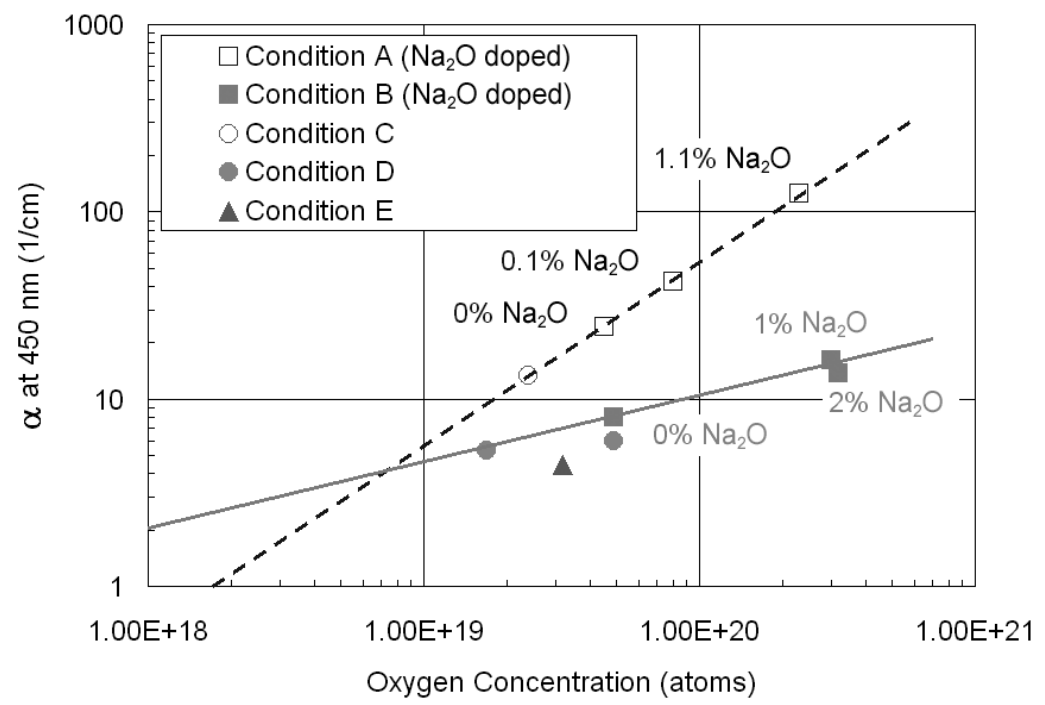

Fig. 4. Relationship between the optical absorption coefficient at $450 \mathrm{~nm}$ and oxygen concentration. 


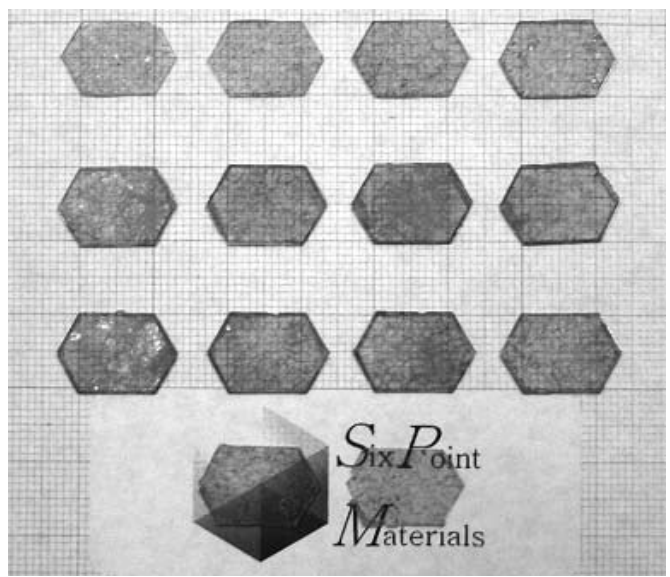

Fig. 5. Examples of GaN wafers fabricated from single bulk GaN crystal.

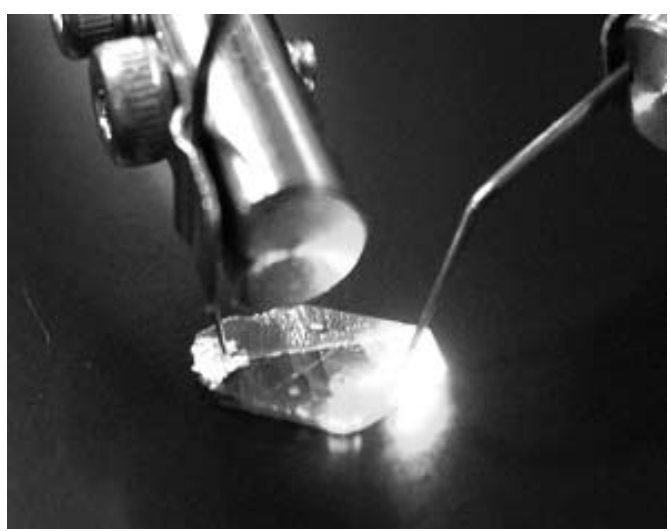

Fig. 6. Example of blue LED fabricated on an ammonothermal GaN wafer.

a blue LED fabricated on a GaN wafer grown by the ammonothermal method. High structural quality and improved optical transparency will ensure the high performance of LEDs at higher output powers.

\subsection{Future prospects}

As discussed above, the ammonothermal method can produce high-quality GaN with a practical throughput. To commercialize this technology, GaN crystals of 2" size or higher must be developed. Expansion of the crystal size involves the following 
challenges: 1) the development of a large reactor, 2) the development of large-area seed crystals, and 3) the reduction of cracks. At SixPoint, we are developing a prototype reactor that can grow 2" GaN crystals. The reactor is designed so that the throughput of GaN wafers will exceed that of a typical HVPE system.

Owing to the slower m-plane growth than c-plane or a-plane growth, the lateral expansion of GaN by the ammonothermal method takes an extended amount of time. In the short term, it is necessary to develop large-area seed crystals by other methods such as HVPE. The development of GaN seeds larger than 2" will require extra effort.

Although the current small GaN crystals show an excellent microstructure, the crystals contain several cracks. Cracking seems to be a universal problem for all bulk growth methods. Since the cracking is thought to originate from residual stress, expansion of the crystal size will make the situation more challenging. Currently, SixPoint is developing an expandable technology to minimize the residual stress in small crystals so that crack-free crystals can be obtained after size expansion.

Even with these challenges in commercialization, we believe that the ammonothermal method has the advantages of scalability and throughput. To penetrate the LED market, the GaN substrate cost must be reduced even further. Rather than achieving an evolutionary cost reduction by the existing growth methods, it is desirable to dramatically reduce the substrate price by innovative ammonothermal GaN growth.

\section{Conclusions}

This article reviewed the ammonothermal growth of $\mathrm{GaN}$, which has the potential to realize low-cost, high-quality GaN substrates for high-power LEDs. Currently, small bulk GaN crystals show an excellent microstructure as well as improved crystal color. Further optimization of the crystal growth conditions will result in transparent, highquality $\mathrm{GaN}$ substrates. The fabrication of $\mathrm{GaN}$ wafers is quite straightforward. Bulk GaN crystals can be sliced into wafers with a multiple wire saw and the surface can be lapped and polished to attain an epi-ready surface. Thus, ammonothermal technology is ready to be commercialized. Expansion of the crystal size to 2" requires the development of a large-scale reactor, the preparation of large seed crystals and the reduction of crystal stress. Achieving large, crack-free bulk crystals of $\mathrm{GaN}$ by the ammonothermal method will contribute to the development of high-performance GaN-based devices at a revolutionary low cost.

\section{Acknowledgements}

Part of this work was conducted with support from the Small Business Innovative Research (SBIR) program by the National Science Foundation (NSF), grant number IIP-1142356.

\section{References}

1 K. Motoki, T. Okahisa, R. Hirota, S. Nakahata, K. Uematsu and N. Matsumoto: J. Cryst. Growth 305 (2007) 377. 
2 K. Fujito, S. Kubo, H. Nagaoka, T. Mochizuki, H. Namita and S Nagao: J. Cryst. Growth 311 (2009) 3011.

3 D. Hanser, L. Liu, E. A. Preble, K. Udwary, T. Paskova and K. R. Evans: J. Cryst. Growth 310 (2008) 3953.

4 S. Porowski: MRS Internet J. Nitride Semicond. Res. 4S1 (1999) G1.3.

5 T. Inoue, Y. Seki, O. Oda, S. Kurai, Y. Yamada and T. Taguchi: Phys. Status Solidi (b) 223 (2001) 15.

6 H. Yamane, M. Shimada, T. Sekiguchi and F. J. DiSalvo: J. Cryst. Growth 186 (1998) 8.

7 F. Kawamura, M. Morishita, K. Omae, M. Yoshimura, Y. Mori and T. Sasaki: Jpn. J. Appl. Phys. 42 (2003) L879.

8 R. Dwiliński, R. Doradziński, J. Garczyński, L. Sierzputowski, M. Palczewska, A. Wysmolek and M. Kamińska: MRS Internet J. Nitride Semicond. Res. 3 (1998) 25.

9 D. R. Ketchum and J. W. Kolis: J. Cryst. Growth 222 (2001) 431.

10 A. P. Purdy, R. J. Jouet and C. F. George: Cryst. Growth Des. 2 (2002) 141.

11 R. Dwiliński, R. Doradziński, J. Garczyński, L. Sierzputowski, A. Puchalski, Y. Kanbara, K. Yagi, H. Minakuchi and H. Hayashi: J. Cryst. Growth 310 (2008) 3911.

12 T. Hashimoto, F. Wu, J. S. Speck and S. Nakamura: J. Cryst. Growth 310 (2008) 3907.

13 D. Ehrentraut, E. Meissner and M. Bockowski (ed.): Technology of Gallium Nitride Crystal Growth (Springer, Berlin, 2010) Chaps. 8 and 9.

14 D. Peters: J. Cryst. Growth 104 (1990) 411.

15 R. Dwiliński, A. Wysmolek, J. Baranowski and M. Kamińska: Acta Phys. Pol. A 88 (1995) 833.

16 A. P. Purdy: Chem. Mater. 11 (1999) 1648.

17 M. Callahan, B. G. Wang, K. Rakes, D. Bliss, L. Bouthillette, M. Suscavage and S. Q. Wang: J. Mater. Sci. 41 (2006) 1399.

18 T. Hashimoto, K. Fujito, B. Haskell, P. T. Fini, J. S. Speck and S. Nakamura: J. Cryst. Growth 275 (2005) e 525.

19 R. Dwiliński, R. Doradziński, J. Garczyński, L. P. Sierzputowski and Y. Kanbara: Poland Patent Application P347918 (2001).

20 Y. Kagamitani, D. Ehrentraut, A. Yoshikawa, N. Hoshino, T. Fukuda, S. Kawabata and K. Inaba: Jpn. J. Appl. Phys. 45 (2006) 4018.

21 T. Hashimoto, F. Wu, J. S. Speck and S. Nakamura: Jpn. J. Appl. Phys. 46 (2007) L889.

\section{About the Authors}

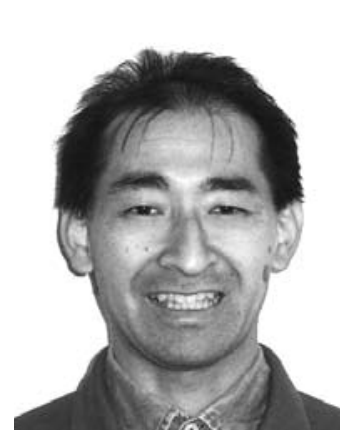

Tadao Hashimoto, Ph.D.

Dr. Hashimoto was awarded a Master of Engineering degree from the Department of Electrical Engineering II, Kyoto University in 1993. He joined Panasonic in 1993, where he worked on gallium nitride crystal growth and aluminum gallium arsenide laser diodes. He was a visiting scholar at the Solid-State Photonics Laboratory, Department of Electrical Engineering, Stanford University from 1998 to 1999 . He left Panasonic in 1999 and joined the graduate program of the Materials Department at the University of California, Santa Barbara (UCSB) in 2000. He was awarded a Ph. D in Materials in 2006 for his research on the ammonothermal growth of GaN. During his stay at UCSB as a postgraduate researcher, he received an outstanding research achievement 
award in 2007. In September 2006, he founded SixPoint Materials to commercialize $\mathrm{GaN}$ wafers by ammonothermal growth. He has published more than 20 technical papers including one in Nature Materials vol. 6 (2007) 568 and has more than 20 world-wide patents. Currently, he is the CEO/CTO of SixPoint Materials, Inc.

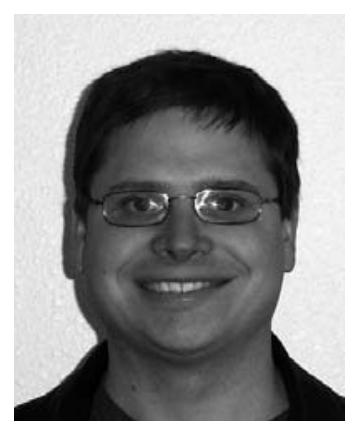

patents.

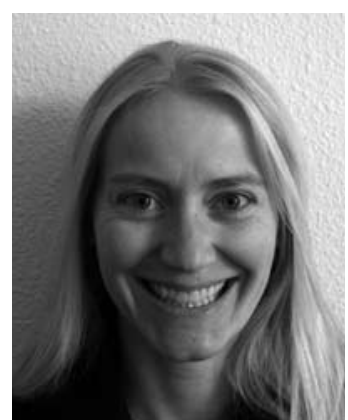

Edward Letts, Ph.D.

Dr. Letts was awarded a Bachelor of Science degree with Honors in Physics from the University of California, Santa Barbara (UCSB), Collage of Creative Studies. He was awarded a Ph. D in Materials in 2007 from UCSB for his research on physical vapor transport of aluminum nitride. During his research at UCSB he was awarded an IGERT Fellowship and a Dean's Fellowship. He co-founded SixPoint Materials, Inc. and currently he is the Vice President of Technology. He has published 5 technical papers and has more than 6 world-wide

\section{Sierra Hoff}

Ms. Hoff was awarded a Bachelor of Engineering degree in optical engineering from the University of Arizona in 2007. After graduation, she joined Nalux and worked on optical measurement and design. She joined SixPoint in May 2010 , and works on crystal growth of gallium nitride by the ammonothermal method. 